\title{
THE PERFORMANCE EFFECTS OF DIVERSIFICATION IN THE CONTEXT OF ITS DECLINE: A META-ANALYTICAL REVIEW
}

Please note: The full version of the paper has been submitted for review to the Journal of Management Studies.

\author{
ANSGAR RICHTER \\ Surrey Business School \\ Rik Medlik Building, \\ University of Surrey, \\ Guildford, Surrey, GU2 7XH \\ United Kingdom \\ Email: a.richter@surrey.ac.uk \\ MONIKA SCHOMMER \\ University of Liverpool \\ Email: m.schommer@liverpool.ac.uk
}

\author{
AMIT KARNA \\ Indian Institute of Management Ahmedabad \\ Email: karna@iima.ac.in
}

\begin{abstract}
We study changes in the performance effects of declining levels of diversification over time. Using results from two meta-analytical approaches (MARA and HOMA), we contribute to literature by arguing that the pressure to reduce diversification has affected those firms particularly strongly whose diversification strategies were most detrimental to firm performance.

\section{INTRODUCTION}

In recent decades, powerful institutional forces as well as market pressures have pushed firms to reduce their level of diversification and focus on fewer, closely related "core" businesses in which they enjoy the greatest competitive advantage (Markides, 1995). According to agencytheoretic (e.g., Kogut, Walker, \& Anand, 2002; Montgomery, 1994) and institutional (e.g., Lee, Peng, \& Lee, 2008; Wan, 2005; Wan \& Hoskisson, 2003) perspectives, increasing shareholder power, a more active market for corporate control, and a liberalized market environment have curbed the ability of managers to pursue potentially value-destroying conglomeration strategies. These developments have led to the "de-institutionalization" of the conglomerate form in the late 1980s and early 1990s in the U.S. (Davis, Diekmann, \& Tinsley, 1994; Fligstein \& Markowitz, 1993; Lichtenberg, 1992). Similar developments have taken place in other Western economies since then (Whittington \& Mayer, 2000). With respect to emerging economies, Lee et al. (2008) and Peng, Seung-Hyun, and Wang (2005) have argued that with increasing institutional development, the relative benefits of diversification have decreased, and its relative costs increased, turning a former diversification premium into a diversification discount. As a result, aggregate levels of diversification among emerging market firms are reported to have decreased, too (Hoskisson, Johnson, Tihanyi, \& White, 2005). Using a meta-analytic review, we investigate
\end{abstract}


changes in the performance effects of diversification in the context of the decline in levels of diversification over time.

\section{DIVERSIFICATION AND ITS PERFORMANCE EFFECTS \\ Conceptual Foundations}

Three main insights emerge from our review of the strategy and the finance literatures on the diversification-firm performance relationship. First, low levels and related types of diversification are more likely to have positive firm performance consequences, whereas high levels and less related types of diversification strategies are more likely to have negative performance effects, yet there is considerable variation in the performance effects of both related and unrelated diversification across firms (Rumelt, 1974). Second, no consensus has emerged with respect to the question of whether the mean effect of diversification on performance effect is positive or negative. The answer to this question appears to be subject to methodological choices and the type of the performance measure used. Furthermore, both temporal factors and the institutional environment in which the diversification-performance relationship is studied appear to play a role. Third, there appears to be considerable heterogeneity among firms in terms of their ability to manage diversification (Klein \& Lien, 2009). Scholars have found significant differences between firms with low and high levels of diversification (Amit \& Livnat, 1988). Some highly diversified firms outperform their focused yet otherwise similar competitors (Campa \& Kedia, 2002; Kuppuswamy \& Villalonga, 2010). We thus argue that the performance effects of diversification can more usefully be conceived as a variable that is likely to follow the pattern of a normal distribution (see Figure 1). In this view, some firms will be more successful in managing a given degree of diversification better than others, due to their underlying resource endowments (Barney, 1991; Chatterjee \& Wernerfelt, 1991), capabilities (Adner \& Helfat, 2003; Teece, 2007), or as a result of other firm characteristics or unknown factors (Rumelt, 1991) (see Mackey, Barney \& Dotson, 2017). For example, Klein and Saidenberg (2010) have shown that the performance effects of diversification (measured by both profitability and capital market valuations) in a sample of bank holding companies depended on the organizational structure of the companies concerned. George and Kabir (2012) found that the impact of diversification on outcomes such as survival differed substantially among the firms in their sample, owing to the heterogeneity in ownership structures. Against this background, we now discuss the effects that environmental pressures have had on both levels of (different types of) diversification and on its performance implications.

Insert Figure 1 about here

\section{Diversification and its Performance Effects in the Context of Environmental Changes}

There is widespread agreement that overall levels of diversification among large firms have been decreasing since the 1980s. The "deinstitutionalization" of the diversified model of the corporation appears to have started in the late 1970s and early 1980s in the U.S. (Chandler, 1990). Since then, similar developments have taken place in other Western countries (Basu, 2010). Although levels of diversification remain high in the integrated business groups prevalent in many emerging economies (Khanna \& Palepu, 2000; Khanna \& Rivkin, 2001), even in these countries there are clear signs of a trend towards de-diversification (Hoskisson et al., 2005).

According to different strands of literature, three inter-related sets of forces account for the decline in levels of diversification. First, changes in factor markets, specifically a general shift in 
the balance of power from managers towards shareholders (Kochan \& Useem, 1992; Useem, 1993), and other capital market pressures, have curbed the ability of managers to engage in managerial empire building (Hope \& Thomas, 2008). Diversification strategies may help managers to maximize their own utility at the expense of shareholders (Shleifer \& Vishny, 1989). More well-developed and efficient external capital markets are more likely to penalize firms through share price discounts which, in turn, raise the likelihood of takeover (Hoskisson \& Turk, 1990; Shleifer \& Vishny, 1991).

Second, greater competition in product markets has forced firms to focus on those lines of business where they have the clearest advantage over their competitors (Peteraf, 1993; Teece, 1980), rather than to compete on scale by acquiring firms in other lines of business.

Third, changes in the institutional environment have supported the two developments sketched above (e.g., through greater deregulation, privatization and capital market liberalization) by favoring a reduction in diversification in more direct ways (Lee et al., 2008).

The environmental pressure towards greater de-diversification should have affected in particular those firms with higher levels and more unrelated forms of diversification to start with, than firms with low levels and more related forms of diversification. We therefore expect that the decrease in levels of unrelated diversification will be significantly greater than the change in levels of related diversification. As a result, overall levels of diversification, which represent the aggregate effects of the expected reduction in unrelated diversification and any changes in related diversification, should have declined, too.

The environmental pressures discussed above will have affected not only the level of diversification, but also the strength of the effect of diversification on (alternative measures of) firm performance, as a result of a twofold selection process. First, the pressure to de-diversify should have been stronger for firms with more unrelated diversification strategies than for firms pursuing more related ones, as the former are more likely to have negative effects on performance than the latter. Second, comparing firms with a given level of diversification yet with heterogeneous resource and capability endowments, the pressure to reduce their degree of diversification should have been strongest for those firms that were least capable of managing their diversification in a value-enhancing manner (Mackey et al., 2017). As a result, firms with particularly value-destructive diversification strategies should have been forced to de-diversify otherwise, they may have been "weeded out" through takeover and subsequent break-up, or through decline and exit. In contrast, firms with greater capacity to manage diversification successfully, and thus with better performance, should have had greater likelihood of survival (McKelvey \& Aldrich, 1983). Comparisons of representative samples of diversified firms in a given economy over time should thus contain a larger proportion of firms with positive performance consequences. As a result, the aggregate (mean) performance effect of diversification will have improved. Our argument is depicted graphically in Figure 1 by the rightward shift in the distribution of performance effects of diversification, with the change in the mean performance effect from $\bar{r}_{0}$ to $\bar{r}_{1}$.

Furthermore, the performance consequences of unrelated diversification among the fewer, remaining firms pursuing this strategy will have become better, as firms with greater capacities to manage unrelated diversification should have faced less pressure to refocus than firms with weaker capabilities for doing so. As a result, the gap between the mean performance effect of unrelated diversification as compared to the mean performance effect of related diversification should have declined. In sum, we expect the heterogeneity in the performance effects of (different types of) diversification to have become smaller. 


\section{DATA AND METHODS}

We use meta-analysis (Hunter \& Schmidt, 1990; Lipsey \& Wilson, 2001), an "analysis of analyses" (Glass, 1976), in order to review the empirical findings on the diversificationperformance relationship to date, and test the influence of contextual factors on this relationship. In addition to Hedges-Olkin (1985) meta-analysis (HOMA), we apply meta-analytical regression analysis (MARA), using effect size measures denoting the strength of the relationship between diversification and performance as the dependent variable (Hunter \& Schmidt, 1990; Lipsey \& Wilson, 2001). Our sample comprises studies published between 1962 and 2016 and data collected between 1950 and 2011. We use a total of 267 primary studies containing 387 effect sizes and over 150,000 firm-level observations from over 60 years of research on the diversification-firm performance relationship.

\section{MAIN FINDINGS AND DISCUSSION}

Our meta-analyses provide two main insights: First, overall levels of diversification have declined, at least when diversification is measured by the Herfindahl index. When the Entropy index of diversification is used, this decline is visible, too, although the coefficient on the time variable is not statistically significant. However, when running the analysis separately for levels of related diversification and for levels unrelated diversification, we find interesting differences in their development over time. Unrelated diversification seems to have declined in a linear fashion. In contrast, levels of related diversification appear to have increased again since the mid-1990s, following an initial decrease in the late 1970s and during the 1980s. Our analysis with respect to levels of diversification thus suggests that the pressure to de-diversify over time has not been uniform across the samples of firms taken into consideration.

Second, our study suggests that in the context of its overall long-term decline, the relationship between related and unrelated diversification on the one hand, and performance outcomes on the other, has changed considerably, too. If one disregards these changes, this relationship appears familiar in that it is consistent with the findings produced in previous studies: Our MARA confirms the results by Schüle (1992), Palich et al. (2000) and Bausch and Pils (2009) of a curvilinear relationship between diversification and performance, in that related diversification has a significant positive effect, and unrelated diversification a negative and significant one on performance, with the overall (aggregate) effect size of -0.04 (our HOMA, which uses an even larger sample than the MARA, shows an aggregate effect size of -0.03). This finding holds true for both accounting-based performance and for capital market performance measures. However, there has been a considerable decline in the strength of the mean performance effects of diversification over time. HOMA shows that this reduction in the magnitude of the overall performance effect was driven entirely by the decline in the performance effect of unrelated diversification. Our MARA confirms the significance of the time variable on the mean performance effect of unrelated diversification. In contrast, the mean performance effect of related diversification remained virtually unchanged during this period of time.

These findings support our theoretical argument, according to which both levels of (related and unrelated) diversification, and its effects on performance vary not only across environmental conditions, but also over time. Furthermore, there is also considerable variation in the mean performance effects across samples, as indicated by the standard errors of the mean effect sizes in our HOMA. 
Our findings suggest that there is considerable variation in the performance effects of diversification at the sample level. The strategic management literature is concerned with explaining variations in the performance across firms on the basis of heterogeneity in resources, capabilities and other firm-specific factors (Adner \& Helfat, 2003; Hoopes \& Madsen, 2008). Firms are neither all-alike, nor are they all-unique (McKelvey \& Aldrich, 1983). Extant research has already identified firm-specific factors such as organization structure (Klein \& Saidenberg, 2010) and ownership structure (George \& Kabir, 2012) as factors that materially affect the performance consequences of diversification. Furthermore, there is evidence that some firms are better at creating synergies from related diversification, or at using internal capital markets in the pursuit of unrelated diversification, than other firms. Scholars have also identified environmental factors such as institutional development and changes in regulation as affecting diversification and its performance effects (Lee et al., 2008).

Our study contributes to the strategic management literature by challenging the conventional wisdom that the shape of the diversification-performance relationship is inherently U-shaped. We believe that this particular shape of the relationship may have been historically contingent on a weak selection environment that allowed relatively many firms to pursue unrelated diversification strategies with detrimental performance outcomes. Our results are in line with those of previous studies (e.g., Bausch \& Pils, 2009; Palich et al., 2000), that levels of unrelated diversification declined significantly and continuously following their peak in the 1970s. It is indicative that in the last decade of our investigation (the period since 2000), we found only 13 studies reporting performance effects of unrelated diversification, as compared to considerably larger numbers of studies in the decades before. For the lower number of firms pursuing this strategy, the performance implications of unrelated diversification appear to be considerably better than was the case in earlier decades. Thus, the right-hand side of the inverted U-shaped relationship between diversification and performance appears to have become flatter over time. Our analysis leaves open the question of whether these changes are the result of the dropping out of firms with particularly poor performance consequences of the samples used in the primary studies taken into account in our meta-analysis, or the result of learning effects (firms improving their capacity to manage unrelated diversification).

Our approach provides a temporal perspective on the debate (largely led in the finance literature) as to whether the effects of diversification on performance and capital market valuations are negative or positive (Campa \& Kedia, 2002; Kuppuswamy \& Villalonga, 2010; Rajan, Servaes, \& Zingales, 2000). Much of this debate has focused on unrelated ("conglomerate") forms of diversification. From our point of view, the answer to this question may depend, among other factors (e.g., methodological ones), on whether earlier or later data were used in the empirical studies concerned. We challenge the view that diversification is "good" or "bad" per se, concurring with the arguments by Mackay et al. (2017(, Klein and Lien's (2009) and others that firms are heterogeneous in their capacity to manage diversification. This heterogeneity applies not only to cross-sectional comparisons among firms, but also to their development over time.

\section{CONCLUSION}

Despite the limitations of our analysis, we believe our study has provided clear indications that both levels of (different types of) diversification, and its relationships with firm performance, have changed over time. As levels of diversification have declined, so has the effect of diversification, and of unrelated diversification in particular, on firm performance. Our 
study calls for greater emphasis to be put on the temporal nature of the phenomena considered in strategic management research.

Figure 1: Theoretical distribution of diversification-performance correlations



REFERENCES AVAILABLE FROM THE AUTHORS

Please note: The full version of the paper has been submitted for review to the Journal of Management Studies. 